\title{
HIV Antibody Seroprevalence and Determinants Amongst Antenatal Clients in a Tertiary Hospital in the Niger Delta
}

\author{
Kotingo E. L. MBBS, DMAS, FMAS, FWACS \\ Allagoa D.O. B. Med (Pharm), MBBS, FWACS, DMAS, FMAS, \\ Cert ART Cleverland USA, Dip HSM (Israel), FICS \\ Department of Obstetrics and Gynaecology, Federal Medical Centre, \\ Yenagoa, Bayelsa State, Nigeria
}

Doi: 10.19044/esj.2018.v14n9p300 URL:http://dx.doi.org/10.19044/esj.2018.v14n9p300

\begin{abstract}
Background: The pandemicity of the human immunodeficiency virus (HIV) has continued to be a 'medical quagmire,' one of the most serious global catastrophe and public health problem that plagues the world today. Objectives: To determine the seroprevalence and clinico-epidemiological correlates of HIV infection in pregnancy. Methodology: This is a descriptive cross sectional study. Two hundred and twenty (220) consecutive healthy pregnant women attending the antenatal booking clinic of the hospital who met the inclusion criteria were recruited. Data was collected via a questionnaire. Data entry and analysis was done using SPSS (statistical package for social sciences) 22 statistical package (SPSS Inc., Illinois, U.S.A). $\mathrm{P}$ value less than 0.05 was taken as being significant. Results: Of the 220 women, $4.6 \%(n=10)$ were seropositive for HIV antibodies. Multiple sexual partners was the significant risk factors for HIV seropositivity $(\mathrm{p}<0.05)$. There was no significant association with respect to tattoo/scarification marks, female circumcision, previous blood transfusion, intravenous drug abuse or sharing of sharps, previous surgery, episiotomies or dilatation and curettage ( $>0.05$ ). Conclusion: The high endemicity of HIV infection in this study justifies the need for routine screening in pregnancy to identify and institute treatment of the infection promptly as this will reduce the mother to child transmission of the virus. Sex education on the dangers of multiple sexual partners or sexual promiscuity, availability of barrier methods of contraception and patronage, more efforts/interventions by relevant agencies, high sense of vigilance amongst others are very vital to curtailing this global pandemic in our society.
\end{abstract}

Keywords: HIV infection, HIV determinants, seroprevalence, pregnancy 


\section{Introduction}

The pandemicity of the human immunodeficiency virus (HIV) cannot be overemphasized as it has continued to be a 'medical quagmire,' one of the most serious global catastrophe and public health problem that plagues the world today. Acquired immunodeficiency syndrome (AIDS) has killed more than 25 million people since its discovery in 1981(UNAIDS, 2006). The Joint United Nations Programme on HIV/AIDS (UNAIDS) estimated that, in 2008, approximately 33.4 million people worldwide $(1 \%$ of the global adult population aged $15-49$ years) were infected with HIV; $67 \%$ of all people living with HIV worldwide live in sub-Saharan Africa, and $91 \%$ of all new infections among children occur there (UNAIDS, 2009).

HIV/AIDS continues to strain the struggling health system of many developing countries and remains a threat to health in Nigeria as it has encumbered and reversed many developmental gains of the recent past including maternal and under-five mortality rates. Currently with an estimated population of 193,854,816 (Worldometers, 2017) and an annual growth rate estimated to be $2.63 \%$ in 2017 as reported by the United Nations (Worldometers, 2017) , Nigeria is the most populated country in sub-Saharan Africa and after South Africa, Nigeria has the second largest number of people living with HIV in the world. To buttress this, one out of every 11 persons live with the virus in the country (NACA, 2011).

Nigeria is responsible for $30 \%$ of the global burden of mother to child transmission (MTCT) of HIV, and is one of the 22 focal countries of the Global Plan to Eliminate MTCT. This is in contrast to the developed countries like Australia and the Netherlands where MTCT is 0.23 per 100 and 0.26 per 100, respectively. (UNAIDS, 2011, Spencer JD et al, 2003, Vanderbij AH et al, 2003).

The first two AIDS cases in Nigeria was diagnosed in 1985 and reported in 1986 in Lagos one of which was a young female sex worker aged 13 years from one of the West African countries. (Nasidi, A. \& Harry, T.O. 2006). Sequel to this, the Nigerian Government adopted Ante Natal Care (ANC) sentinel surveillance as the system for assessing the epidemic. The first HIV Sentinel Survey in 1991 showed a prevalence of $1.8 \%$. Subsequent surveys revealed a progressively increasing prevalence of $3.8 \%$ in 1993, $4.5 \%$ in $1996,5.4 \%$ in $1999,5.8 \%$ in 2001 and $5.0 \%$ in 2003 . In 2005, the prevalence declined; $4.4 \%$ in $2005,4.6 \%$ in 2008, $4.1 \%$ in 2010 (FMH report, 2010). and 3.4\% in 20I2 (Olokor O, 2013). Even though there was a steady decline from $4.6 \%$ in 2008 to $3.4 \%$ in 2012 , it's still a far cry from the $1.8 \%$ in 1991.

Whereas evidence suggests that pregnancy has little or no effect on HIV progression in asymptomatic women or women with early infection. However, in symptomatic patients when HIV is more advanced, it results in 
an increase in certain pregnancy complications such as intrauterine growth retardation, preterm birth, and low birth weight. Obstetric and or gynaecological factors like early age at first coitus, low parity, a history of termination of pregnancy, and hospital delivery were identified as risk factors for HIV infection among pregnant women. (Smith NH \& Hwang LY. 1996, Pettifor AE et al, 2004, Perry D et al, 2002, Etukumana EA et al, 2011)

A public health approach based primarily on information and educational programme focussed on ways of preventing HIV acquisition by women of the reproductive age group and their partners remains the gold standard for tackling the HIV epidemic and its associated problems, Secondarily, this includes tackling the unmet needs of contraception among HIV positive women and the prevention of mother to child transmission of HIV. (Evelyn UI \& Osafu O, 1999).

\section{Objectives}

The general objective is to determine the seroprevalence and clinicoepidemiological correlates of HIV infection in pregnancy in Yenagoa.

The specific objectives are (1) To find out the seroprevalence of HIV antibodies in pregnant women that present in clinic. (2) To identify known risk factors for HIV infection in pregnant women. (3) To make evidence based recommendations on screening protocols for our obstetric population.

\section{Methodology}

\section{Study Area}

This study was carried out at the Antenatal clinic of the Federal Medical Centre, Yenagoa, Bayelsa state in the South-south region of Nigeria between $4^{\text {th }}$ September to $28^{\text {th }}$ October, 2016.

\section{Study design}

A descriptive cross sectional study.

\section{Inclusion criteria}

This included all pregnant women who presented for booking at the antenatal clinic of FMC Yenagoa and gave consent.

\section{Exclusion criteria}

- $\quad$ This included all pregnant women who declined to participate.

- Patients who withheld their consent for inclusion in the study.

\section{Sample size}

The sample size was calculated using the statistical formula (Araoye MO, 2003) based on reported prevalence rate of HIV antibody of $4.9 \%$ 
(Ibrahim, I. A, et al, 2013) from previous a study and a confidence interval of 95\%.

\section{Study population}

The minimum sample size was thus calculated to be 86 with an attrition of $20 \%$. However, a total of 220 consecutive healthy pregnant women attending the antenatal booking clinic of the hospital who met the inclusion criteria were recruited into this study after pre test counselling and obtaining consent from them. This was tested for antibodies to HIV-1 and HIV-2.

\section{Sample collection and processing}

Five millilitres $(5 \mathrm{ml})$ of peripheral venous blood was collected from consecutive subjects in the antenatal booking clinic into plain sterile bottles. Blood samples were centrifuged for ten minutes at $6,000 \mathrm{rpm}$, serum was obtained and stored at $-20^{\circ} \mathrm{C}$ until used.

Samples were analysed in batches with commercially available in vitro diagnostic kits (one step test strips). The HIV-1/2 one step test is a rapid lateral flow immunoassay which qualitatively detects the presence of antibodies in serum utilizing a combination of monoclonal and polyclonal antibodies to HIV-1 and HIV-2. The membrane is percolated with recombinant antigen and synthetic peptide on the test line region of the strip. During testing, the serum specimen reacts with the particles coated with HIV-1/2 antigen. The mixture migrates upward on the membrane chromatographically by capillary action to react with antibodies to HIV $1 / 2$ on the membrane and generate a coloured line in the test region. Chase buffer is required for whole blood testing.

To serve as procedural control, a coloured line always appeared at the control line region indicating that proper volume of specimen had been added and membrane wicking had occurred. Tests in which two distinct red lines appeared, one in the control region and another in the test region, was regarded as positive. Tests in which only the control line was distinctly coloured red was recorded as negative while tests in which the control line fails to appear was regarded as invalid and was repeated.

\section{Questionnaire}

Women were enrolled and underwent pretest counselling and were administered a structured interviewer- administered questionnaire.

\section{Data analysis}

Data was analysed using SPSS (statistical package for social sciences) 22 statistical package (SPSS Inc., Illinois, U.S.A). Univariate analysis for categorical variables was performed using chi-square. $\mathrm{P}$ value less than 0.05 was taken as being significant. 


\section{Ethical considerations}

Approval for the study was obtained from the ethical committee of the Federal Medical Centre, Yenagoa. The study was carefully explained to the patients and their informed consent obtained before being recruited into the study.

\section{Results}

A total of two hundred and twenty (220) pregnant women were interviewed.

The mean age of the pregnant women studied was 28.8 years \pm 5.2 . The predominant age group was 20-29 years (50.0\%). Majority $(50.0 \%)$ of the respondents were from the Ijaw ethnic group and it is followed closely by the Igbo ethnic group (28.2\%). Most (96.8\%) of the respondents were Christians. Majority $(41.8 \%)$ of the respondents were involved in doing business as an occupation. Majority (91.8\%) also of the respondents were married, and most of the marriages were of the polygamous type or setting (83.7\%). Most $(77.8 \%)$ had a secondary education.

Amongst those that agreed that the virus could be transmitted from person to person, $15(51.7 \%)$ said it is through blood/blood products; while $10(34.5 \%)$ said it is through sexual intercourse; and $2(6.9 \%)$ said it is through body fluids- urine, saliva and physical contact with infected persons.

Twelve $(5.5 \%)$ of the respondents said yes, that the virus could be transmitted from a mother to her baby, while 206 (94.5\%) did not know if there could be transmission of the viruses from a mother to her baby. Amongst those that said yes, $4(33.3 \%)$ said the infection occurs during delivery; while $5(41.7 \%)$ do not know how the transmission occurs; 2 (16.7\%) said it occurs in-utero; and $1(8.3 \%)$ said it occurs during breastfeeding.

Majority $(72.6 \%)$ of the respondents has had more than one sexual partner in their life. Most $(85.3 \%)$ of the respondents did not know if their spouses had other sexual partners. Eighty-five point nine percent (85.9\%) said they have not had sexually transmitted infections in the past; and $94 \%$ of the respondents has not had transfusion of blood and blood products; $96.8 \%$ do not share needles/blades with other people; and $98.6 \%$ do not inject illicit drugs. There is a statistically significant association between respondents with more than one sexual partner and Seroprevalence of HIV Infection $\left(X^{2}=5.59\right.$, df $=1, \mathrm{P}<0.05)$.

Table1: Result of HIV antibody test amongst respondents.

\begin{tabular}{lccc}
\hline $\begin{array}{l}\text { Variables } \\
\text { Total }\end{array}$ & & & \\
& Reactive & Frequency $(\%)$ & \\
& $10(4.6)$ & $210(95.4)$ & 220 \\
\hline $\begin{array}{l}\text { Retroviral screening } \\
(100.0)\end{array}$ & & & \\
\hline
\end{tabular}


antibody

Four point six percent $(4.6 \%)$ of the respondents were reactive to HIV

Table 2: The prevalence of HIV antibody amongst the different parity groups.

\begin{tabular}{llc}
\hline Variables & \multicolumn{2}{c}{$\begin{array}{c}\text { Frequency (\%) } \\
\text { Retroviral screening }\end{array}$} \\
& Reactive & Non reactive \\
\hline Parity & $5(50.0)$ & $117(55.7)$ \\
$0-1$ & $3(30.0)$ & $51(24.3)$ \\
$2-3$ & $0(0)$ & $25(11.9)$ \\
$4-5$ & $2(20.0)$ & $10(4.8)$ \\
$6-7$ & $0(0)$ & $7(3.3)$ \\
$8-9$ & $\mathbf{1 0}(\mathbf{1 0 0 . 0})$ & $\mathbf{2 1 0}(\mathbf{1 0 0 . 0})$ \\
Total & & \\
\hline
\end{tabular}

Reactivity to the retroviral screening test was highest (50\%) amongst the $0-1$ parity group; followed closely by the $2-3$ parity group with $30 \%$; and the $6-7$ parity group with $20 \%$ reactivity. The mean parity was $1.20 \pm$ 1.16 .

Table 3: The prevalence of HIV antibody amongst the different gestational age (GA) groups.

\begin{tabular}{lll}
\hline Variables & \multicolumn{2}{c}{$\begin{array}{c}\text { Frequency (\%) } \\
\text { Retroviral screening } \\
\text { Non reactive }\end{array}$} \\
\hline GA (In weeks) & Reactive & $32(15.2)$ \\
$1-10$ & $1(10.0)$ & $73(34.8)$ \\
$11-20$ & $5(50.0)$ & $69(32.9)$ \\
$21-30$ & $3(30.0)$ & $36(17.1)$ \\
$31-40$ & $1(10.0)$ & $\mathbf{2 1 0}(\mathbf{1 0 0 . 0})$ \\
Total & $\mathbf{1 0 ( 1 0 0 . 0 )}$ & \\
\hline
\end{tabular}

The prevalence of retroviral disease was $5(50.0 \%)$ in those of GA 11 - 20 weeks; 3 (30.0\%) amongst those with GA 21 - 30 weeks; and $1(10 \%)$ amongst those with GA $1-10$, and $31-40$ weeks.

Table 4: The relationship between retroviral disease positivity and gestational age (GA).

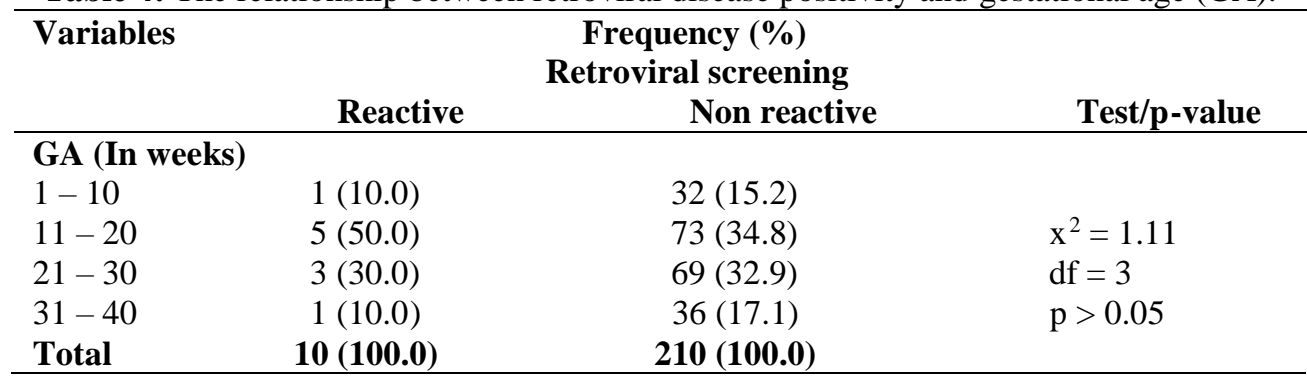

From the results of $\mathrm{X}^{2}$ statistics in the table above, gestational age was not found to statistically related to higher positivity of retroviral disease. 
Table 5: Risk factors/transmission mechanisms of retroviral disease.

\begin{tabular}{|c|c|c|c|}
\hline \multirow[t]{2}{*}{ Variables } & \multicolumn{2}{|c|}{ Frequency $(\%)$} & \multirow[t]{2}{*}{ Total } \\
\hline & No & I don't know & \\
\hline \multirow{2}{*}{\multicolumn{4}{|c|}{$\begin{array}{l}\text { Have you had surgery in the past } \\
\text { If yes specify }\end{array}$}} \\
\hline & & & \\
\hline Appendectomy & $11(39.3)$ & $0(0)$ & \\
\hline Caesarean section & 15 (53.6) & $0(0)$ & \\
\hline Ectopic surgery & $2(7.1)$ & $0(0)$ & \\
\hline Total & $28(100.0)$ & $\mathbf{0}(\mathbf{0})$ & \\
\hline Do you have any tattoos? Scarification marks & $2(0.9)$ & $213(99.1)$ & $215(100.0)$ \\
\hline Were you circumcised & $24(10.9)$ & $196(89.1)$ & $220(100.0)$ \\
\hline \multicolumn{4}{|l|}{ Have you procured an abortion by dilatation and curettage } \\
\hline & $18(8.2)$ & $201(91.8)$ & $219(100.0)$ \\
\hline Have you ever been given episiotomy during delivery & $4(1.8)$ & $216(98.2)$ & $220(100.0)$ \\
\hline Have you ever had blood /blood product transfusion & $13(6.0)$ & $205(94.0)$ & $218(100.0)$ \\
\hline illicit(hard) drugs & $3(1.4)$ & $216(98.6)$ & $219(100.0)$ \\
\hline
\end{tabular}

Amongst the respondents, 28 (12.8\%) has had surgeries in the past; 11 (39.3\%) has had appendectomy; while 15 (53.6\%); and $2(7.1 \%)$ has had caesarean section and ectopic surgeries respectively.

Two $(0.9 \%)$ of the respondents had tattoo and scarification marks, while most $213(99.1 \%)$ had none. Twenty four $(10.9 \%)$ of the respondents were circumcised; while $18(8.2 \%)$ had procured abortion by dilation and curettage; $4(1.8 \%)$ has had episiotomy given to them during delivery in the past.

Table 6: The relationship between age, level of educational of respondents and retroviral screening positivity.

\begin{tabular}{|c|c|c|c|}
\hline Variables & frequency $(\%)$ & $\begin{array}{l}\text { Retroviral screening } \\
\text { Reactive }(\%)\end{array}$ & Test/ p value \\
\hline \multicolumn{4}{|c|}{ Age as at last birthday in years $(\mathrm{N}=220)$} \\
\hline $10-19$ & $9(4.0)$ & $1(10.0)$ & \\
\hline $20-29$ & $110(50.0)$ & $4(40.0)$ & $x^{2}=1.96$ \\
\hline $30-39$ & $93(42.3)$ & $4(40.0)$ & $\mathrm{df}=3$ \\
\hline $40-49$ & $8(3.6)$ & $1(10.0)$ & $\mathrm{p}>0.05$ \\
\hline \multicolumn{4}{|c|}{ Level of education $(N=194)$} \\
\hline None & $0(0)$ & $0(0)$ & \\
\hline Primary & $7(3.6)$ & $1(10.0)$ & $\mathrm{x}^{2}=1.38$ \\
\hline Secondary & $151(77.8)$ & $8(80.0)$ & $\mathrm{df}=3$ \\
\hline Tertiary & $36(18.6)$ & $1(10.0)$ & $\mathrm{p}>0.05$ \\
\hline
\end{tabular}

From the results of $X^{2}$ statistics in the table above, age and level of education of respondents were not found to be statistically related to higher positivity of retroviral disease. 


\section{Discussion}

This is a hospital based study to determine the burden of HIV infection in our obstetric population looking at the seroprevalence, risk factors and clinico-epidemiological correlates of HIV infection in pregnancy.

The seroprevalence of HIV antibodies in our pregnant women population was $4.6 \%$. This figure conforms to the Center for Disease Control and Prevention (CDC) cut off of $>1.2 \%$ for high risk populations. (CDC, 2006). and it is similar to the $4.9 \%$ that was reported in Niger Delta University Teaching Hospital (NDUTH), Okolobiri, Bayelsa state. (Ibrahim, I. A, et al, 2013). This is not surprising as both hospitals are tertiary health facilities in the same state and share similar sociocultural characteristics. Other similar prevalences were found in Cross River (4.4\%) and Ondo state(4.3\%). (FMH report, 2013). According to the Federal Ministry of Health, 2013. National HIV \& AIDS and Reproductive Health Survey, the prevalence of $4.6 \%$ in our study was higher than the national prevalence of $3.4 \%$, Abia (3.3\%), Osun (2.6\%), Imo (2.5\%), Lagos (2.2\%), Enugu (1.3\%) and Delta state $(0.7 \%)$ amongst others. It is however lower than figures from Rivers (15.2\%), Taraba (10.5\%), Kaduna (9.2\%), Federal Capital Territory (7.5\%) and Akwa Ibom state $(6.5 \%)$ to say the least. (FMH report, 2013).

There seems to be an upward trend of the prevalence of HIV infection in Bayelsa state. Prevalence of 2.7\% (FMH report, 2013) in 2012 when compared to our study with a prevalence of $4.6 \%$. Poverty, reduced emphasis on education, lack of continuous advocacy and increased promiscuity in view of the current economic condition in addition to poor funding by relevant agencies saddled to undertake the responsibility to curb the scourge may account for the upward trend. This means that more efforts/interventions should be geared towards halting, reducing or reversing this alarming rate.

In this study, the seroprevalence of HIV antibody was found to be highest amongst the $20-29$ and 30-39 age group with $40.0 \%$ seroprevalence each. There was a fall with an abrupt decline afterwards. This was supported by the 2010 HIV survey in Nigeria (NACA, 2014) where the infection is more prevalent among the 20-39 year age group. Similar findings of 25-29 years age group were reported in the Uyo (Nyoyoko N. P. \& Umoh A.V, 2016), Nnewi (Umeononihu OS et al, 2013) and Tanzanian (Msuya SE et al, 2006) studies. However, in Harare, Zimbabwe (Mbizvo MT et al, 2001) women aged 17 years and below had the highest incidence $(6.25 \%)$ followed by those aged 18 -19 years $(5.42 \%)$. From the above, one may not be wrong to say that the HIV infection in women occur at a younger age, during the first few years after sexual debut. This also is in keeping with previous studies which reveals that women in their sexually active years and at the peak of their child bearing years are the most affected as the major route of transmission of the virus is 
through heterosexual intercourse in our environment. (Ekure EN \& Etuk SJ, 2001, Duru MU et al, 2009). However, there was no statistical significance between age and HIV antibody seropositivity in this study ( $\mathrm{p}>0.05)$.

Educational status, occupation, parity and age at last birthday were not identified as risk factors of HIV infection in this study; this is in contrast with other studies performed in similar institutions which revealed these as risk factors of HIV infection. (Duru MU et al, 2009, Smith NH \& Hwang LY, 1996). Majority (50.0\%) of the women were from the Ijaw ethnic group and it is followed closely by the Igbo ethnic group (28.2\%). Most (96.8\%) were Christians. Majority (41.8\%) were involved in doing business as an occupation. Majority (91.8\%) also were married, and most of the marriages were of the polygamous type or setting (83.7\%). Most (77.8\%) had a secondary education. Being the only urban tertiary facility serving as a referral center to the people of Bayelsa state and its environs, it's thus open and accessible to all calibers of patients. This may explain the differences above.

There was a statistically significant association between women with more than one sexual partner and seroprevalence of HIV Infection (X2 $=5.59$, $\mathrm{df}=1, \mathrm{P}<0.05)$. Majority $(72.5 \%)$ of the obstetric women have had a history of multiple sexual partners in their life and in addition, most (85.3\%) of them did not know if their spouses had other sexual partners. Ibrahim, I. A. et al reported similar finding in NDUTH, Okolobiri, Bayelsa state. (Ibrahim, I. A, et al, 2013)

Amongst the women, $28(12.8 \%)$ have had surgeries in the past; 11 $(39.3 \%)$ had appendectomy; while $15(53.6 \%)$; and $2(7.1 \%)$ have had caesarean section and ectopic surgeries respectively.

Tattoo and scarification marks $(0.9 \%)$, circumcision $(10.9 \%)$, abortion by dilation and curettage $(8.2 \%)$, surgeries $(12.8 \%)$, blood transfusion $(6.0 \%)$ and illicit drug (1.4\%) use were not identified as risk factors to HIV seropositivity in this study. Possible explainations are; The cultural practice in this environment is on the decline, as such it is not a surprising occurrence; Concerning abortion, it could be because most of the $\mathrm{D}$ and $\mathrm{C}$ was done in the hospital and the instruments used could have been well sterilized; This may have been due to the aversion to receiving blood among our people; In Nigeria, illicit (hard) drugs including narcotics are strictly under control and attract severe sanctions thus limiting availability and or accessibility.

\section{Conclusion}

The high endemicity of HIV infection in this study according to Center for Disease Control and Prevention, justifies the need for routine screening in pregnancy to identify and institute treatment of the infection promptly as this will reduce the mother to child transmission of the virus. Sex education on the dangers of multiple sexual partners or sexual promiscuity, availability of 
barrier methods of contraception and patronage, more efforts/interventions by relevant agencies, high sense of vigilance amongst others are very vital to curtailing this global pandemic in our society.

\section{References:}

1. Report on the global AIDS epidemic. Geneva, UNAIDS. (2006). Available http://www.unaids.org/enJHIV_datal2006GlobalReport/default.asp(A ccessed 12 July 2006).

2. Joint United Nations Programme on HIV/AIDS. AIDS epidemic update (2009). Available at http://bit.ly/iHUsZK. (Accessed June 17 2011).

3. Worldometers. (2017) Elaboration of data by United Nations, Department of Economic and Social Affairs, Population Division. World Population Prospects: The Revision. Available at Www.Worldometers.info

4. NACA (2011). Joint Annual Review of National Response to HI V/AIDS. 201; p. 103.

5. Federal Ministry of Health. (2005) HIV/AIDS sentinels seroprevalence survey in Nigeria technical report. Abuja: Federal Ministry of Health.

6. UNAIDS (2011). Unified Budget Results and Accountability Framework (UBRAF) 2012-2015 Country case study: Nigeria. In: Proceedings of the 28th meeting of the UNAIDS Program Coordinating Board. Geneva: UNAIDS.

7. Spencer JD, Tibbits D, Tippet C, Mead C, Kaldor JM. (2003) Review of antenatal testing policies and practice for HIV and hepatitis C infection. Aust New Zealand Pub Health; 27: 614-9.

8. Vanderbij AH, Mulder-Folkents DK, Vanden Hock JA, Boerk SMF, Coutinho RA (2003). HIV screening among pregnant women in the region of Amsterdam in 2002. Ned Tijdschr Geneeskd 2003; 147: 1232-6.

9. Nasidi, A. \& Harry, T.O. (2006) The epidemiology of HIV/AIDS in Nigeria. In: Adeyi, O., Kanki, P.J., Odutolu, O., Idoko, J.A. (Eds.), AIDS in Nigeria: A Nation on the Threshold. Harvard Center for Population and Development Studies, Cambridge (Massachusetts) Available: http://www.apin.harvard.edu/Chapter2.pdf (accessed 7 February 2012).

10. Federal Ministry of Health Technical Report (2010). National HIV Sero-prevalence Sentinel Survey among Pregnant Women Attending Clinics in Nigeria. Government of Nigeria: Abuja. P. 96 
11. Olokor O. (2013). Punch: Rivers state has the highest HIV/AIDS rate FG. 8 Dec 2013. (Internet). Available at http://www.punchng. com/news/rivers-has-highest-hivaidsrate-fg

12. Smith NH \& Hwang LY. (1996). Risk factors for HIV in pregnant women. Int J STD AIDS; 7: 388-95.

13. Pettifor AE, Vander Straten A, Dunbar MS, Shiboski SC, Padian NS. (2004). Early age of first sex; a risk factor for HIV infection among women in Zimbabwe. Int J STD AIDS; 18: 1435-42.

14. Perry D, Reid M, Thame M, Fletcher H, Mullings A, McCaw-Binns A. (2002) HIV infection seroprevalence and risk factors among pregnant women attending the antenatal clinic at the University hospital of West Indies, Kingston, Jamaica. West Indian Med J; 51: 80-3.

15. Etukumana EA, Tharcher TD, Sagay AS. (2011). Obstetrics risk of HIV infection among antenatal women in a rural Nigerian hospital. Nig Med; 52: 24-7.

16. Evelyn UI, Osafu O. (1999). Sexual behaviour and perception of AIDS among adolescent girls in Benin City, Nigeria. Afr J Reprod Health; 3: 39-44.

17. Araoye MO (2003). Subjects Selection. In: Research Methodology with statistics for Health and Social sciences. Ilorin. Nathadex publishers: pp. 115-129.

18. CDC. (2006) Revised recommendations for HIV testing of adults, adolescents, and pregnant women in health-care settings. MMWR;55(RR14):1-17.

19. Ibrahim, I. A, Owoeye, G. I, O, Obilahi, A. (2013) The Burden of HIV Infection among Women Attending Antenatal Clinic in a Semi-urban Nigerian Town. West Indian Med. J. Special, Vol. 62 Issue 4, p323328. 6p.

20. Federal Ministry of Health (2013). National HIV \& AIDS and Reproductive Health Survey 2012, NARHS Plus II. Abuja.

21. National Agency for the Control of AIDS (NACA) Nigeria GARPR (2014). Abuja, Nigeria: 2014. Federal Republic of Nigeria: Global AIDS Response Country Progress Report.

22. Nyoyoko N. P. \& Umoh A.V. (2016) The prevalence and determinants of HIV seroconversion among booked ante natal clients in the University of Uyo teaching hospital, Uyo Akwa Ibom State. Nigeria. Pan Afr Med J; 25: 247.

23. Umeononihu OS, Ikechebelu JI, Okonkwo JE, Udigwe GO, Mbachu II. (2013) The prevalence of HIV sero-positivity in late pregnancy among antenatal attendees with seronegative status in first half of pregnancy in Nnewi, South East Nigeria. J HIV Hum Reprod [serial 
online];1:25-9. [cited 2013 Dec 20] Available from: http://www.jhhr.org/text.asp?2013/1/1/25/116533.

24. Msuya SE, Mbizvo E, Hussain A, Uriyo J, Sam NE, Stray-Pedersen B. (2006) HIV among pregnant women in Moshi Tanzania: the role of sexual behavior, male partner characteristics and sexually transmitted infections. AIDS Res Ther. 17;3:27.

25. Mbizvo MT, Kasule J, Mahomed K, Nathoo K. (2001) HIV-1 seroconversion incidence following pregnancy and delivery among women seronegative at recruitment in Harare, Zimbabwe. Cent Afr J Med;47(5):115-8.

26. Ekure EN \& Etuk SJ. (2001). Factors influencing HIV seroprevalence rate among pregnant women in Calabar, Nigeria. J Sex Health Matters. Available from: http://www.sexualhealthmatters.com/v3iss1/article3.html

27. Duru MU, Aluyi HSA, Anukam KC. (2009). Rapid screening for coinfection of HIV and HBC in pregnant women in Benin City, Edo State, Nigeria. Afr Health Sci; 9: 137-42.

28. Smith NH \& Hwang LY. (1996) Risk factors for HIV in pregnant women. Int J STD AIDS; 7: 388-95. 